amendments were identified along with the need for clearer regulations for strengthened enforcement.

Conclusions To achieve the Master Plan Thailand needs to improve its road safety management system, make coordination at all levels more effective, strengthen law enforcement including heavier penalties, amend several road safety laws and promulgate new laws.

\section{IMPROVING STATE DRUG OVERDOSE FATALITY (DOF) SURVEILLANCE USING POLICY AND EPIDEMIOLOGICAL TOOLS}

${ }^{1}$ Svetla Slavova, ${ }^{1}$ Terry Bunn, 'Sarah LaMantia, ${ }^{2}$ Tracey Corey. ${ }^{1}$ Kentucky Injury Prevention and Research Centre, USA; ${ }^{2}$ Office of the Chief Medical Examiner, Kentucky, USA

10.1136/injuryprev-2016-042156.424

Background Kentucky (Ky) had the $2^{\text {nd }}$ highest DOF rate in the U.S. in $2012(25 / 100,000)$ mainly due to prescription drug (PD) overdose (PDO). In response, Ky enacted comprehensive PDO prevention laws. The law evaluation required death certificates (DCs) with accurate drug overdose data.

Methods In KY, DCs are completed by elected county coroners. In 2011, 30\% of the Ky DCs did not list any drugs contributing to DOFs, underestimating the burden of PDO deaths. DOF reporting based on a DC data alone didn't allow monitoring of PDO by specific drugs and identifying sources of diversion.

Results To improve the completeness of DOF data Ky enacted a law in 2013 (KRS72.026) requiring the coroners to test for controlled substances postmortem if a cause of death was not clearly established; the toxicology testing is performed by an accredited national laboratory, and is paid by the Kentucky Medical Examiner Office (MEO). KY's Chief Medical Examiner reviews all of the test results, and follows up with a review of DCs, and consultation with coroners on a case-by-case basis. Two years after law implementation, there is a significant increase in completeness of DOF data. To further improve the quality of DOF data, the MEO expanded coroners' education and supplemented autopsy reports with DC cause of death completion suggestions. The OME and Ky Injury Prevention and Research Centre expanded the KyDOF surveillance, incorporating DC, death investigation, autopsy, toxicology, and prescription drug monitoring data. New epi tools were introduced to analyse the comprehensive KyDOF data. Data showed the PDO prevention laws contributed to better prescribing and decreased diversion of historically abused medications (e.g., oxycodone, alprazolam); and identified heroin and fentanyl (mostly illicitly manufactured) as emerging drugs of abuse.

Conclusions Quality DOF data are critical to inform targeted policy interventions and evaluate effectiveness.

\section{CHILD INJURY PREVENTION IN CHINA, EVIDENCE BASED POLICY DEVELOPMENT}

\section{Zhu Xu. UNICEF China Office}

\subsection{6/injuryprev-2016-042156.425}

Background As infectious diseases have well controlled and become less common, death due to injury has become the leading cause of mortality among children aged between one and 18 years in China. Every year, more than 80,000 Chinese children die due to unintentional injury, and at least 10 million under the age of 18 are injured, of whom 8 million are treated in hospitals. Methods In recognition of this, UNICEF has developed country program on child injury prevention (CIP) and strategic support on advocating government policy and implementation of CIP. The evidence of child injury issues has been presented to the government through population based child injury survey in Beijing City (2003) and Jiangxi Province (2005), and it has been confirmed that injury is the leading cause of death for children in China. As requested by government, the CIP project in China aiming on policy advocacy and CIP intervention have been developed in UNICEF cooperated project with government of China.

Results National policy on CIP developed by National Working Committee for Children and Women through China National Program for Child Development (2011-2020). One sixth reduction of child injury mortality target goal set up in this national plan. Child injury prevention pilots supported by UNICEF developed through implementation safe home, safe school, and safe community activities. The CIP implementation sites has increased from beginning 3 counties supported by UNICEF to 29 counties by both government and UNICEF so far.

Conclusions The results of CIP project show that it is feasible to implementing child injury prevention through established government service system from health, education, community, and public security and safety etc. The evidence for advocating CIP development, demonstration of CIP implementation, and technical support on guidance of safe home, safe school, safe community, and monitoring system needed to help government building CIP system.

\section{COMMUNITY PARTICIPATION IN LAW ENFORCEMENT IN ROAD SAFETY - YANGON, MYANMAR}

Zaw Myo Han, Myo Aung Myint, Aung Ko Oo, Kyaw Htwe. No.2 Traffic Police Division, Yangon, Myanmar

\subsection{6/injuryprev-2016-042156.426}

Background Myanmar is expressing escalating level of fatalities as motorization increases. Agencies acknowledged the existing weakness in proper data system, weakness in legislation, insufficient funding, a need for measurable road safety targets and lack of effective and scalable implementation to address risk behaviour.

Police commanders and road safety professionals have a responsibility to think strategically about traffic policing and enforcement. Police must actively work with partners and the community, working together for common aims. Myanmar Traffic Police, Yangon division introduced OCC (Online Complaint Centre) where the police and community share a partnership in the broadest sense for responsibility and accountability for road safety.

Methods From the mobile phones social application 'Viber' is used to upload photo and reports of those who broke the traffic rules or commenced risky behaviour to Yangon Traffic Police on hotline number.

The traffic police interact transparently and appropriately with alleged citizens, advertise the vehicle numbers in daily newspapers and weekly journals and penalise according to the existing laws together with Road Transport Administrative Department, City Development Committee and multi bus line control committee. 